\title{
O trem, a fábrica e as caatingas: perspectivas de modernização do sertão baiano na Primeira República
}

\section{The train, the factory and the "caatingas": perspectives of modernization of Bahia's backland in First Brazilian Republic}

\author{
Eudes Marciel Barros Guimarães*
}

\begin{abstract}
Resumo
Com a instalação de uma fábrica de produção variada e a possibilidade da chegada de uma linha férrea no começo da década de 1910, houve grandes expectativas por parte de alguns moradores do alto sertão baiano empenhados na modernização da região, em consonância com o ritmo que se projetava para o Brasil. Para isso, enfatizavam o potencial econômico das terras do sertão e a necessidade de explorá-las, tendo em vista a variedade e as riquezas naturais das caatingas. Mas as perspectivas que tinham no horizonte deram lugar, inúmeras vezes, a frustrações que redimensionaram suas experiências ao longo do tempo.
\end{abstract}

Palavras-chave: Modernização; alto sertão da Bahia; imaginário social.

\begin{abstract}
With the installation of a factory and the possibility to introduce a railroad in the early 1910s, there were great expectations by some engaged men in the modernization of the region called "alto sertão da Bahia" [high hinterland in Bahia], according to the growth rate that was projected for Brazil. For this, they emphasized the economic power of backlands and the need to explore them, bearing in mind the variety and natural resources of the "caatingas". However promising experiences that they had were substituted, often, to sorrow frustration along the after years.
\end{abstract}

Keywords: Modernization; upper backland of Bahia; social imaginary.

*Doutorando em História pela Universidade Estadual Paulista (UNESP-Franca).E-mail: eudesembg@yahoo. com.br 
No início da década de 1910, o engenheiro agrônomo Mario Spinola Teixeira liderava um grupo de acionistas num arriscado investimento: levar a cabo a ideia de construir uma "indústria" na vila de Bella Flor, numa zona sertaneja baiana distando cerca de 700 quilômetros da capital do estado. A ideia, elaborada pelo próprio Mario, efetivou-se com o empreendimento que levou um nome sugestivo: Empreza Industrial Sertaneja, cujo efeito semântico parecia ser calculado pelo engenheiro. Num só tempo, essas três palavras indicam o jogo capitalista, as expectativas de desenvolvimento traçadas para o país e a designação de um espaço ainda inexplorado, mas com variedade de riquezas naturais celebrada tanto em jornais quanto em discursos de parlamentares estaduais e federais. ${ }^{1}$

A empreitada carregada de ousadia tornou-se temerária no juízo dos demais acionistas. Mario Teixeira, na contramão dos seus sócios, insistiu no projeto, ganhando até matéria laudatória na imprensa local, que o apelidou de "homem de ferro" diante de sua persistência na ideia e de sua inegável atração pelos objetos mecânicos e pela atmosfera instaurada desde a Revolução Científico-Tecnológica de fins do século XIX. Conforme a mesma reportagem, datada de 1912, o engenheiro foi ao Rio de Janeiro em busca de auxílio do governo federal e da diminuição de impostos, pautando-se sobretudo no argumento de "desenvolver o aproveitamento das riquezas naturaes" daquela vasta zona do sertão. Enquanto isso, aponta ainda o jornal, os demais acionistas, "com as mãos na cabeça, lastimavam ter por alli o seu rico dinheirinho á mercê de sonhados resultados que, ao seu modo de ver, redundariam em prejuizos enormes". ${ }^{2}$ Malgrado todos os percalços, entre desconfianças e tremendas dificuldades infraestruturais, o projeto foi efetivado.

Numa viagem a passeio realizada pelas bandas de Bella Flor (atual cidade de Guanambi), nos idos de abril de 1912, Antonio Neves, habitante da cidade vizinha Caetité, ${ }^{3}$ fez notar as impressões que lhe ocorreram numa

\footnotetext{
${ }^{1}$ Sobre esse assunto, cf. BARTELT, Dawid Danilo. Sertão, República e Nação. Trad. Johannes Krestschmer e Raquel Abi-Sâmara. São Paulo: Edusp, 2009.

2“Empreza Industrial Sertaneja”. A Penna, Caetité-BA, 02 de ago. 1912, p. 2-3. As edições deste jornal estão conservadas no Arquivo Público Municipal de Caetité, que dispõe ao pesquisador interessado as versões digitalizadas para consulta.

${ }^{3}$ Durante muito tempo, Caetité foi o principal núcleo urbano da região. Como sintetizou a historiadora Maria de Fátima Novaes Pires, "Caetité pertencia à região de entroncamento do interior baiano, situação que a ligava internamente à província e à região Sul do Brasil, com trânsitos comerciais desde o Setecentos. As tropas foram as grandes responsáveis por esses intercâmbios, com franca atividade até as primeiras décadas do século XX. A sua economia, essencialmente agropastoril, possibilitou acúmulo de grandes fortunas, principalmente no século XIX, quando figurava como "celeiro do sertão", abastecendo regiões em seu entorno, a exemplo da Chapada Diamantina, além dos negócios realizados em outras partes da província
} 
visita à sede da Empreza. Logo antes de chegar propriamente à vila, num raio de poucos quilômetros e ao descer as serranias daquele percurso, avistou, pela primeira vez, o edifício que se fazia notar de longe. Não era, a seu ver, "uma construcção elegante, feita sob as regras da architectura, dando assim a distancia a apparencia do corpo de uma d'essas egrejas do sertão”. Mas existiam, ali, sinais claros que ofereciam à percepção algo novo. Ao fundo do edifício, continuou Neves,

[havia] a casa aonde se acham instaladas as caldeiras, de cujo telhado emergem duas largas e altas chaminés, semelhante a de todas essas fabricas, cujas machinas são movidas a vapor; as quaes n'aquela hora lançavam ao ar grossos novellos de fumo, que se elevavam lentamente, espalhando-se pouco a pouco no ambiente, até se diluir, confundindo-se no tom esbranquiçado da tarde. ${ }^{4}$

Naquele confim da Bahia, pouco mais de quinze léguas do rio São Francisco, na direção oeste, e menos de cem quilômetros da fronteira com Minas Gerais, a sudoeste, situava-se Bella Flor, com sua fábrica que constituía uma estranha caixa de ressonância da investida moderna - uma investida tão paradoxal quanto na impressão, descrita pelo viajante, de máquinas a vapor, caldeiras e chaminés fumegantes alojadas em paredes que remetiam às rústicas igrejas dos tempos coloniais. Ali, naquela região referenciada como alto sertão baiano, notadamente pela distância em relação ao litoral, formava-se uma rede de homens interessados nas propostas de modernização, mas pouco afeitos à modernidade num sentido amplo. Seguindo a linha de raciocínio de Raymundo Faoro, "a modernidade compromete, no seu processo, toda a sociedade", por isso amplia o raio de expansão das diversas camadas sociais; diferentemente, "a modernização, pelo seu toque voluntário, se não voluntarista, chega à sociedade por meio de um grupo condutor que, privilegiando-se, privilegia os setores dominantes". Se tivessem no horizonte a modernidade, os grupos dirigentes coordenariam e organizariam o movimento, mas, no âmbito da modernização, o objetivo era dirigi-la, conduzi-la e promovê-la. ${ }^{5}$

Mais estritamente, era do ponto de vista técnico-industrial que se desejava efetivar a modernização. A celebração da máquina, do vapor e da velocidade ganhava o espírito de jornalistas, políticos, sanitaristas, engenheiros

\footnotetext{
da Bahia, do Brasil e do exterior. Essa riqueza, advinda de sua privilegiada situação, possibilitou-lhe uma precoce aparelhagem urbana: Correios (1832), Telégrafo (1896), Typographia (1897), Água Encanada (a partir de 1919), Luz Elétrica (1925) e Banco do Brasil (1943)". PIRES, Maria de Fátima Novaes. Hommes de lettres na "corte do sertão": João Gumes e a escrita social. Veredas da História, ano IV, 2º semestre 2011, p. 154-155.

${ }^{4}$ NEVES, Antonio. "Impressões de viagem". A Penna, Caetité-BA, 05 de jul. 2012, p. 2-3.

${ }^{5}$ FAORO, Raymundo. A República inacabada. São Paulo: Globo, 2007, p. 125.
} 
e demais membros da elite local. ${ }^{6}$ Expressavam-se na imprensa, sobretudo no jornal A Penna, publicado na cidade de Caetité e encabeçado por João Gumes, que era, na época, um dos grandes entusiastas do avanço científico-tecnológico. Nesse jornal pode-se notar a rede de relações tecida por esses homens em função da modernização do alto sertão baiano [mapa 1], ${ }^{7}$ de modo a promover a canalização de objetivos e a formação de uma opinião pública no contexto

Mapa 1 - Localização do alto sertão baiano. Destaque para algumas das principais cidades, inclusive Guanambi (antiga vila de Bella Flor), onde Mario Teixeira construiu sua Empreza

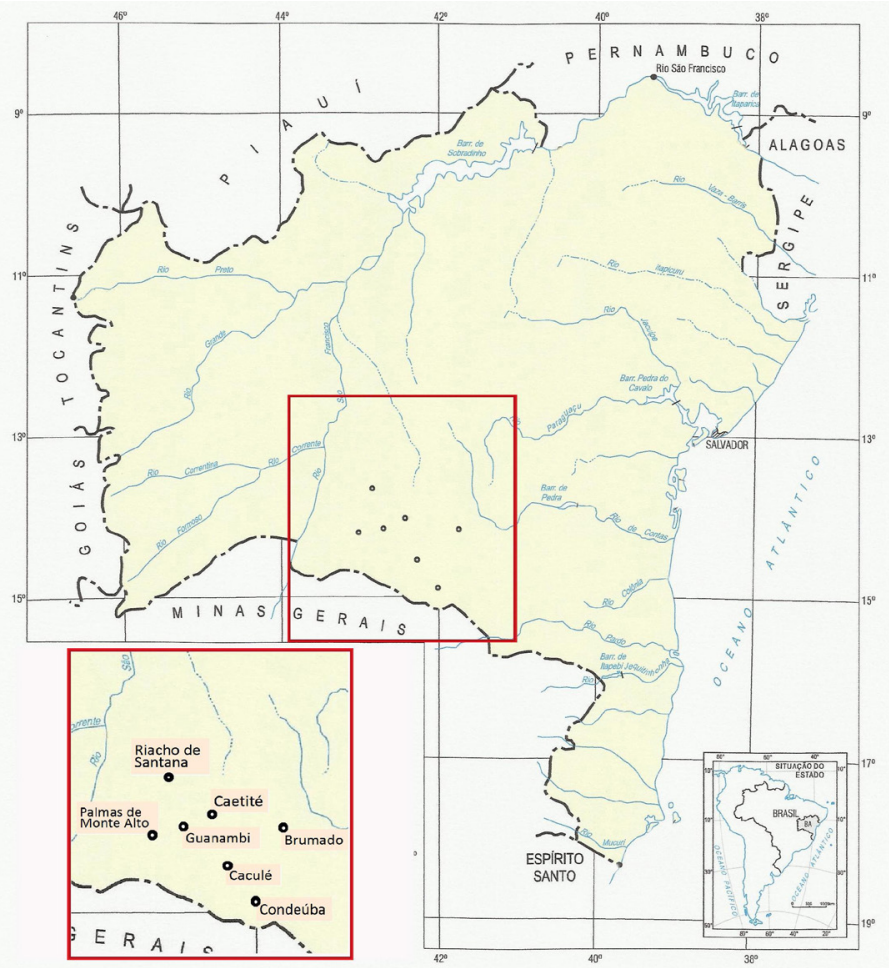

Fonte: SEI - Superintendência de Estudos Econômicos e Sociais da Bahia, 2007 (adaptado). ${ }^{6}$ Cf. SANTOS, Paulo Henrique Duque. Manifestações modernizadoras no alto sertão baiano - Caetité (1910-1920). Anais do VI Simpósio Nacional Estado e Poder: Cultura. UFS, Aracaju, 2010.

${ }^{7} \mathrm{O}$ mapa que o leitor tem em vista neste artigo foi elaborado a partir do Mapa Hidrográfico do Estado da Bahia produzido pela Superintendência de Estudos Econômicos e Sociais da Bahia (SEI, 2007). Fiz um enquadramento de modo a localizar o espaço designado como "alto sertão baiano", que não tem necessariamente fronteiras definidas. Uma discussão sobre esse recorte espacial enquanto região pode ser lida em GUIMARÃES, Eudes Marciel Barros. Um painel com cangalhas e bicicletas: os (des)caminhos da modernidade no alto sertão da Bahia (Caetité, 1910-1930). Dissertação (Mestrado em História) UNESP, Franca, 2012, p. 20-33. 
republicano, acompanhando o ritmo de sua emergência nos principais meios de comunicação do país.

A palavra mágica de então era "indústria" e o seu conceito "era suficientemente abrangente e plástico para abrigar as atividades agrícolas, desde que receptivas aos aperfeiçoamentos técnicos". ${ }^{8}$ Com a instalação da Empreza Industrial Sertaneja, cujo escopo consistia justamente na utilização de aperfeiçoados métodos tanto na exploração agropecuária quanto na fabricação de produtos a partir da matéria-prima disponível, abriu-se um largo horizonte de expectativas diante da investida moderna. Alargou-se ainda mais com a possibilidade da chegada de uma linha da Estrada de Ferro Central da Bahia. Os homens empenhados na modernização regional faziam saber da existência de um potencial econômico nas terras do alto sertão, insistindo nas riquezas das caatingas à revelia dos discursos de depauperação desse ambiente. Para explorá-las, era necessário o investimento dos governos estadual e federal, mas também a instrução do trabalhador sertanejo na lida com as lavouras. Nas linhas seguintes, procuro demonstrar alguns aspectos de um imaginário sustentado pela celebração da máquina e da técnica como elementos orquestradores de novas experiências vislumbradas como promissoras e modernas.

\section{Tudo o mais era caatinga}

Não que o argumento utilizado por Mario Teixeira - no intuito de angariar fundos do governo para a sua empresa - fosse infalível, mas por certo era bastante convincente. No limiar da República, conforme afirma Dawid Bartelt, "o tópos da riqueza adormecida, diferentemente do que significou no Império, transformou-se numa tese de caráter político: a miséria no sertão não seria apenas um resultado da seca, mas também um resultado da infraestrutura inexistente". ${ }^{9}$ O mais grave de todos os desacertos, para um agrônomo atinado da época, seria a indiferença diante das terras feracíssimas, das matas inexploradas, dos descuidos com a criação pecuária.

Se em fins do Oitocentos os ambientes naturais daquelas zonas sertanejas baianas eram qualificados como salubres e até mesmo terapêuticos, ${ }^{10}$ o discurso sanitarista do século seguinte mudou radicalmente esse quadro. Os movimentos de saúde pública das décadas de 1910 e 1920 constataram as

\footnotetext{
${ }^{8}$ HARDMAN, Francisco Foot. Trem-fantasma: a ferrovia Madeira-Mamoré e a modernidade na selva. 2. ed. rev. e ampl. São Paulo: Companhia das Letras, 2005, p. 85.

${ }^{9}$ BARTELT, Sertão, República e Nação, p. 251.

${ }^{10}$ Cf. CHERNOVIZ, Pedro Luiz Napoleão. Diccionario de medicina popular. Pariz: A. Roger \& F. Chernoviz, 1890, p. 318-319.
} 
péssimas condições sanitárias do interior brasileiro, o que incluía, obviamente, os vastos sertões baianos. ${ }^{11}$ Maculada a imagem de uma terra onde era propício o tratamento de doenças, a natureza passou a circunscrever-se numa potencialidade econômica em latência, de modo que, numa conjectura de visionários, poder-se-ia explorar todos os recursos disponíveis no solo, além de promover o plantio de todas as espécies vegetais cultiváveis e consumíveis. Essa visão, compartilhada por Mario e por muitos de seus conterrâneos, encontrava campo fecundo nos debates sobre o futuro da República. Na Câmara dos Deputados da Bahia a busca por soluções para os problemas socioeconômicos do interior do estado ganhou lugar de destaque na pauta. Mas isso não significou necessariamente a presença ativa dos setores governamentais de nível estadual ou federal nos planos regionais de desenvolvimento econômico das terras que se estendiam para além do Recôncavo.

Por outro lado, os discursos sobre a seca instituíram um cenário de morbidez para a vegetação sertaneja. ${ }^{12}$ Com grande eloquência, a publicação de Os Sertões, de Euclides da Cunha, contribuiu decisivamente para o imaginário que se estava criando. Os exemplares poderiam ser adquiridos com facilidade nas livrarias cariocas, mas também pelas mãos de um homme de lettres como João Gumes, ${ }^{13}$ na cidade de Caetité, poucos anos depois da primeira publicação datada de 1902. Nesse livro, ao falar das caatingas, Euclides da Cunha a compara com "uma estepe nua", com a diferença de que nesta "o viajante tem o desafogo de um horizonte largo e a perspectiva das planuras francas". Embrenhado nos sertões de caatinga, é na perspectiva do viajante que o autor compõe a narrativa. Ali, os vegetais existentes formam um emaranhado de espinhos que o desorienta e o estonteia, sem sequer um desafogo. Diante do seu olhar desdobra-se um ambiente de "árvores sem folhas, e galhos estorcidos e secos, revoltos, entrecruzados, apontando rijamente no espaço ou estirando-se flexuosos pelo solo, lembrando um bracejar imenso, de tortura, da flora agonizante...". ${ }^{14}$ É um cenário brutal que se apresenta, exigindo sempre a "luta pela vida" - um ambiente em plena ruína, imagem que é sustentada visualmente na fotografia de Flávio de Barros registradas também no calor da famigerada campanha de Canudos. ${ }^{15}$

\footnotetext{
${ }^{11}$ Cf. LIMA, Nísia Trindade. Um sertão chamado Brasil: intelectuais e representação geográfica da identidade nacional. Rio de Janeiro: Revan, 1999.

${ }^{12}$ BARTELT, Sertão, República e Nação, p. 590.

${ }^{13}$ Para a expressão homme de lettres usada no caso de João Gumes, cf. PIRES. "Hommes de lettres na 'corte do sertão"', p. 151-169.

${ }^{14}$ CUNHA, Euclides da. Os Sertões. São Paulo: Círculo do Livro, 1975, p. 38.

${ }^{15}$ BRIZUELA, Natália. "A fotografia às margens da história: os sertões". In: Fotografia e Império:
} 
Em 1927, o geógrafo alemão Otto Quelle viajava pelo interior baiano quando, depois de dias rodeado pela vegetação que parecia se esquivar de uma classificação sumária, encontrou numa "novela regional", adquirida na cidade de Xique-Xique, ${ }^{16}$ a sentença que lhe pareceu mais plausível para qualificá-la: "A caatinga é a mata baixa" - essas são as palavras iniciais de Vida sertaneja, livro da autoria de Prado Ribeiro lançado naquele mesmo ano. Uma tal definição, tão apressada e pouco convincente, que parece fugir às exigências tanto do argumento científico como da estética literária, revela, contudo, as dificuldades de descrição de um ambiente natural associado, com as oscilações cabíveis, à rigorosidade climática das secas, à pretensa paisagem identitária sertaneja e ao tópos da riqueza adormecida.

No relato do geógrafo alemão, entretanto, a visão homogeneizadora parece insistir - talvez devedora da sensação de monotonia que acompanhava o viajante e certamente instilada pela percepção de uma paisagem calcinada -, ainda mais depois de se confirmar o "genuino anno de sêcca" que estava transcorrendo. A frase supracitada de Prado Ribeiro, incluída nas notas de viagem, foi complementada pelo cientista de acordo com suas impressões:

Um interminavel oceano de mattaria enche a extensa planura a Léste do grande
rio até o sopé da montanha. Despidas de folhas erguem-se as arvores de côr
cinzenta clara, de 4-6 metros de altura, cerradas, uma juncto a outra; durante
horas e horas segue-se a cavallo, o corpo inclinado para a frente, estas extensas
e silenciosas mattas, que exhibem apenas uma camada extremamente fina de
sólo decomposto. ${ }^{17}$

Sem dúvida foram percebidas as variações da paisagem ao longo do trajeto desde a "Bahia meridional ao valle do São Francisco". Na primeira parte do roteiro, saindo de Nazaré, cidade próxima a Salvador, impressionou-lhe a vivacidade das regiões cortadas pelas ferrovias, como eram os casos de Jequiriçá e Jaguaquara. Mas, depois de galgado o "altiplano de Conquista", pouco pareceu mudar: tudo o mais era caatinga. No longo trecho pelo alto sertão baiano em direção ao rio São Francisco, "matto xerophilo arbustivo cérca ao viajante; ao invés de picadas enlameadas, apresentam-se caminhos poeirentos". ${ }^{18}$

Nesse sentido, é sintomático que o autor da "novela regional" citada por Quelle tenha decidido iniciá-la tratando da caatinga. Certamente porque ela,

paisagens para um Brasil moderno. Trad. Marcos Bagno. São Paulo: Companhia da Letras; IMS, 2012, p. 147-184.

${ }^{16}$ Cidade localizada no noroeste da Bahia, à margem do rio São Francisco.

${ }^{17}$ QUELLE, Otto. Relatorio das viagens de estudo na Bahia. Revista do Instituto Historico e Geographico Brasileiro, tomo 106, v. 160, 1929, p. 16.

${ }^{18}$ QUELLE, “Relatorio das viagens de estudo na Bahia...”, p. 12. 
como paisagem, era "elemento essencial"19 para uma abordagem dos "usos, costumes e folclore do sertão baiano", como expressa o subtítulo de Vida sertaneja. Em meados da década de 1920, o livro de Euclides da Cunha já estava bastante conhecido e tornara-se paradigmático para pensar o sertão, a ponto de incomodar autores "sertanejos de nascença", tendenciosos à exaltação da terra numa espécie de regionalismo panegírico - como era o caso de Prado Ribeiro que não via contemplados, na narrativa euclidiana, os aspectos mais característicos das vivências regionais do interior baiano. Aliás, uma alusão pouco ortodoxa ao livro de Euclides não escapou à pena de Ribeiro. Para este último, "o sertanejo é, por circunstâncias etnicas e mesológicas, um triste". ${ }^{20}$ E o olhar proposto não é o do viajante, tampouco do estrangeiro, mas um olhar que se pretende vir de dentro do sertão, (re)conhecendo a "mata baixa" que o rodeia, atribuindo-lhe vida e cores: "Nesse meio áspero e selvagem, as mais originais aves, desde o papagaio ao minúsculo beija- flor, derramam, por todo o intricado da selva, um contínuo e agradável ruido." Tal descrição, que surpreende nos intricados espinhentos a exuberância e a vivacidade, é acrescida de uma expressão do fantástico atribuída àquelas matarias pelos habitantes locais: "Há quem ouça em meio das noites negras e lúgubres, do fundo do matagal, gemidos doloridos de almas penadas, de vaqueiros, ou assobios agudos de caiporas". ${ }^{21}$

Em corografias escritas durante a Primeira República, ganharam destaque os ambientes naturais da região, como nos trabalhos de Pedro Celestino da Silva sobre Caetité e de Tranquilino Torres sobre Condeúba, ${ }^{22}$ ambos publicados na Revista do Instituto Geographico e Historico da Bahia. Ao tratar de Condeúba, Torres escreveu: "É [...] o Município composto de vastas planícies, de terrenos variados e que denominam veredas, caatingas, carrascos [e] campos". ${ }^{23}$ No município de Caetité, Pedro Celestino da Silva distinguiu duas zonas de aproveitamento agrícola: as "caatingas" e os "gerais". Na primeira, "a industria pastoril medra admiravelmente, onde a lavoura é mais disseminada e a população mais densa"; na segunda, "cultiva-se a canna, a mandioca, os cereaes e o café que produz com vantagem" por causa da existência de

\footnotetext{
${ }^{19}$ CAUQUELIN, Anne. A invenção da paisagem. Trad. Marcos Marcionilo. São Paulo: Martins Fontes, 2007 , p. 8. ${ }^{20}$ RIBEIRO, Prado. Vida sertaneja: usos, costumes e folclore do sertão baiano. 2. ed. Rio de Janeiro: F. Briguiet \& Cia. Editores, 1951, p. 19.

${ }^{21}$ RIBEIRO, Vida sertaneja, p. 12-13.

${ }^{22}$ Cidade localizada no sudoeste da Bahia, relativamente próxima a Caetité.

${ }^{23}$ TORRES, Tranquilino L. Memoria descriptiva do municipio de Condeúba. Revista do Instituto Geographico e Historico da Bahia, ano 2, n. 4, junho de 1895, p. 106.
} 
“excellente agua" e "ricas pastagens naturaes". ${ }^{24}$ Esse último autor apontou para inúmeras possibilidades comerciais a partir do cultivo do trigo, da cana-de-açúcar - de onde provinham a rapadura, açúcar e aguardente -, do fumo e do café. As diversas árvores frutíferas e hortaliças também poderiam ser bem aproveitadas. No entanto, toda a produção desses gêneros, quando havia, era em pequena quantidade, e o cultivo, conforme Celestino da Silva, era feito de modo rudimentar e pouco afeito às técnicas agrícolas modernas. $\mathrm{O}$ algodão predominava, ainda segundo o autor, como o principal e mais próspero gênero agrícola, embora não comparável à produção áurea de fins da época colonial, por isso merecia melhor reparo: "O algodão é uma das maiores riquesas actuaes e o seu plantio encontra no municipio terreno apropriado no valle do rio S. João; mas é preciso que sejam os seus cultivadores instruidos no melhor meio de preparar o terreno, expurgar a semente e beneficial-a". ${ }^{25}$

As percepções de uma paisagem agonizante nas extensas zonas sertanejas baianas contrapunham-se às visões de terras feracíssimas de vegetação variegada. Em vista da prevalência da caatinga, a grande maioria dos relatos que dela se ocupou fez notar o intrigante contraste entre o período seco e o chuvoso, quando a paisagem natural muda radicalmente de um cenário acinzentado e mórbido para um verde vibrante. No entanto, aqueles mais empenhados em enaltecer os atributos naturais de sua região afirmavam que, com métodos e investimentos, todas as quadras do ano poderiam ser propícias para trabalhar a terra.

Recentemente, pesquisadores têm examinado a biodiversidade das caatingas, enquanto outros atentam-se para as suas diferentes representações através do tempo. ${ }^{26} \mathrm{Nilo}$ Bernardes, por exemplo, reconheceu a complexidade desse ambiente, apontando para uma extensa área de mais de $800 \mathrm{mil} \mathrm{km}^{2}$, o que designa uma décima parte do território brasileiro. Em geral, a “presença da jurema, regularmente alta, sucedendo-se com freqüência, muitas vezes é o primeiro sinal de que estamos entrando em área de caatinga", repetindo-se também "o pereiro, o pinhão bravo, o marmeleiro, ou ainda, a faveleira, com suas folhas cobertas de espinhos, abundantes no sertão do norte da Bahia e do médio São Francisco". O geógrafo ainda assinalou uma característica biológica

\footnotetext{
${ }^{24}$ SILVA, Pedro Celestino da. Noticias historicas e geographicas do municipio de Caetité. In: Revista do Instituto Geographico e Historico da Bahia, n. 58, 1932, p. 165.

${ }^{25}$ SILVA, “Noticias historicas e geographicas do municipio de Caetité...", p. 165.

${ }^{26}$ Dessas pesquisas, merecem atenção: SIQUEIRA FILHO, José Alves (org.). Flora das Caatingas do Rio São Francisco: História natural e conservação. Rio de Janeiro: Andrea Jakobsson Estúdio Editorial, 2012; e KURY, Lorelai Brilhante (org.). Sertões adentro: viagens nas caatingas, séculos XVI a XIX. Rio de Janeiro: Andrea Jakobsson Estúdio Editorial, 2012.
} 
comum às plantas das zonas de caatinga: "a severa adaptação das espécies vegetais ao rigor da estiagem que se verifica nos sertões. Deve ser lembrado, porém, que varia de região para região a época em que tal fato ocorre". ${ }^{27}$

A região do alto sertão da Bahia é caracterizada como uma zona de transição de caatinga para o cerrado. Constitui, assim, um complexo de fauna e flora e, a depender da altitude dos terrenos, nem sempre se acham as mesmas espécies, como apontou Pedro Celestino da Silva. Nota-se com bastante frequência o porte arbóreo, ainda que esparso em algumas áreas, onde despontam árvores como o angico, a baraúna, a aroeira, o umbu e o juazeiro, sendo este último "de particular significação para os homens e para os animais, por ser a única árvore que conserva sua copa frondosa durante todo o ano". ${ }^{28}$

Para dimensionar a importância dada a essa "riqueza natural" nas primeiras décadas do século XX, basta lembrar que em algumas exposições ocorridas no Brasil ou fora dele havia um lugar para os produtos oriundos do sertão. Em meados do ano de 1928, a Bahia organizava a sua participação na Exposição Ibero Americana de Sevilha. Diante dos trabalhos de coleta do mostruário, foi pedido ao coronel Deocleciano Pires Teixeira, influente político do alto sertão baiano, o envio - com urgência, devido ao curto prazo - de alguns produtos a serem expostos. Entre eles, salientava-se amostras de uma coleção, “a mais completa possível", de madeiras (com explicações da serventia de cada uma); minérios (desde "grafite, calcareos, mármores, quartzo hyalino, crystal de rocha, salitre" a pequenas quantidades de "turmalinas, agua-marinhas, minérios de ouro, prata, platina, amethistas, borylos, topázios, granadas", interessando especialmente os metálicos como os "de ferro, cobre, mangan chromo"); couros e peles ("interessando muito os de giboia e sucury, de que há muito procura na Europa, raposa e gato do matto"); fibras ("10 kilos, pelo menos, bruta, e 10 kilos bem penteada, de cada qualidade"); óleos, sementes oleaginosas e resinas vegetais ("pelo menos um litro de cada qualidade"); produtos alimentares ("principalmente aparas de mandioca, café, cacau, farinha de araruta e de batata") e plantas medicinais ("com explicação do fim para que for empregada"). 0 requerimento, feito em missiva datada de 27 de junho de 1928, termina reafirmando o propósito de destacar a região como parte de um todo chamado Bahia: "Será bom que as amostras de todos esses produtos venham acompanhadas dos preços que gozam ahi, assim como de qualquer outras informações uteis a uma boa propaganda". ${ }^{29}$

\footnotetext{
${ }^{27}$ BERNARDES, Nilo. As caatingas. Estudos Avançados, São Paulo, vol. 13, n. 35, 1999, p. 71-73.

${ }^{28}$ BERNARDES, “As caatingas", p. 71.

${ }^{29}$ Arquivo Público Municipal de Caetité. Fundo: acervo particular da família de Dr. Deocleciano Pires Teixeira;
} 


\section{Uma fábrica no baixio}

Um dos lugares de interesse para a exploração dos ambientes naturais e para o desenvolvimento de lavouras era o baixio onde se situava Bella Flor, terreno propício para a plantação de diversos vegetais, como algodão, milho e arroz. João Gumes fez notar ali uma "paizagem soberba e empolgante", cujo baixio, uma espécie de planície que servia de assento à Serra de Monte Alto, formava "um extenso talude, de declividade quasi imperceptivel á commum apreciação, levemente abaúlado, orlado pelo sulco dos ribeirões [...], eriçado de morros, pequenas cadeias, collinas, extensos largados de formação primitiva [...]". ${ }^{30}$

Foi nesse cenário que Antonio Neves avistou o edifício sede da Empreza Industrial Sertaneja. Ao fundo, no horizonte, via-se as alcantiladas bordas da Serra de Monte Alto, escondendo a vastidão do norte de Minas Gerais. À frente, estendia-se o baixio imenso e diverso, com colinas, montes salientes e grandes rochedos pontudos aqui e acolá, como que ilhados numa vasta planície. Depois de atravessar o arraial de Bella Flor e já adiantada a tarde, Neves seguiu para o edifício da fábrica, guiado pela curiosidade de observar as máquinas em atividade e tomar notas.

De acordo com seus relatos, a produção da Empreza era muito variada, especialmente quando se tratava do algodão como matéria-prima. Das sementes do algodão extraía-se óleo aproveitado "para diferentes fins, como illuminação, a lubrificação de machinas, e o tempero da comida" ${ }^{31}$ A massa que restava das sementes após a extração do óleo era utilizada "como combustivel na fornalha das caldeiras, ou para adubo das terras de lavoura". Sementes de arroz eram descascadas em máquinas próprias para tal fim, daí iam para outro aparelho que separava os grãos chochos, enquanto os bons grãos iam para o ensacamento. Havia, além disso, uma "fabrica de excellente sabão que a Empreza alli creou, preparado com oleo de caroços de algodão, apropriado á lavagem de roupa e a outros usos domésticos". Também encontravam-se "moinhos destinados ao fabrico de farinha ou fubá de milho, de arroz e de caroços de algodão". A farinha deste último servia como alimento para o gado vacum, "tanto para a engorda, como para o notavel augmento da lactação das vacas".

\footnotetext{
grupo: Deocleciano Pires Teixeira; série: correspondências; caixa: 4, maço: 4.

${ }^{30}$ GUMES, João. “Monte Alto”. A Penna, Caetité-BA, 12 de set. 1913, p. 1.

${ }^{31}$ Segundo Antonio Neves, o aproveitamento das sementes de algodão era algo pouco conhecido naqueles sertões, e a extração do óleo era uma novidade trazida pela Empreza, tornando-se, até mesmo, "conforme ouvi-se dizer em muitos logares, um vantajoso succedaneo do toucinho, mormente em epocha de carestia d'esse gênero". NEVES, Antonio. "Impressões de viagem”. A Penna, Caetité-BA, 12 de set. 1913, p. 1.
} 
Mantinha-se, ainda, “ao pé do seu edifício [...], em um pequeno quintal, desprovido de quaesquer hervas ou grammineas forrageiras, uma manada de enormes bois, gordos e nedios, destinados ao corte, alimentado exclusivamente com a farinha de caroços de algodão". ${ }^{32}$ Além de tudo isso, planejava-se montar "uma serraria, para o preparo de tabuas apropriadas á confecção de caixões, em que serão acondicionadas o sabão e outros productos que tenham de sair para o mercado". ${ }^{33}$

O grande edifício e suas máquinas mecânicas instilavam o imaginário dos que com eles mantiveram contato, especialmente no período da montagem. Entretanto, era certamente muito modesta se levados em conta os padrões industriais da época. A arrojada iniciativa de Mario Teixeira foi tomada por Antonio Neves como algo que proporcionaria novos rumos àquele sertão, fazendo lembrar até mesmo os "espiritos que vêm a terra investidos de uma missão da Providência, como os Colombos e os Guttemberg". Nada mais sugestivo como esses personagens relacionados a eventos fundadores - a descoberta do continente americano e a invenção da imprensa - que, conforme Hans Ulrich Gumbrecht, representam metonimicamente o "início da modernidade" ${ }^{34}$. Findando a tarde, ao adentrar a sede da Empreza, o contato pela primeira vez com máquinas movidas a vapor impressionou o visitante:

Ainda de longe ouviamos a estrondosa trepidação das machinas que estavam trabalhando. A espaços, grandes jactos de vapor, chiando asperamente, esguichavam por um tubo, cuja extremidade desemboca no terreiro; um cheiro sui generis, exhalado pela polpa da semente de algodão submettida á cocção, diffundia-se em torno, como um cheirozinho de progresso, na espirituosa expressão dos nossos companheiros de visita; um movimento insolito e alacre observavase em todas as secções dos diversos trabalhos, executados ao mesmo tempo, com perfeita regularidade - concorrendo tudo aquillo para a forte e estranha impressão que experimentei aliás bastante comprehensivel em quem como eu, via pela primeira vez a machina movida a vapor..$^{35}$

Seguindo ainda as notas de Neves, o serviço nas caldeiras era dirigido por um "pratico estrangeiro, [...] de nacionalidade norte-americana". Difícil era suportar a alta temperatura da sala onde elas se encontravam, embora os empregados achassem-se "perfeitamente habituados". As horas de trabalho pareciam metodicamente organizadas, ouvindo-se "já quase ao lusco-fusco

\footnotetext{
${ }^{32}$ NEVES, Antonio.” Impressões de viagem”. A Penna, Caetité-BA, 19 de jul. 1912, p. 2.

${ }^{33}$ NEVES, Antonio. “Impressões de viagem". A Penna, Caetité-BA, 02 de ago. 1912, p. 3.

${ }^{34}$ GUMBRECHT, Hans Ulrich. Modernização dos sentidos. Trad. Lawrence Flores Pereira. São Paulo: Ed. 34, 1998, p. 11-12.

${ }^{35}$ NEVES, Antonio. “Impressões de viagem”. A Penna, Caetité-BA, 19 de jul. 1912, p. 2.
} 
[...] o som prolongado e cheio da buzina que annuncia a dispersão dos operarios e o fechamento do edifício". Ademais, como se fossem uma extensão ou uma imitação da força mecânica, "trabalhavam alguns operarios negros, de troncos nús e musculatura herculea, reluzentes de suor, occupados em retirar com grandes pás de ferro a polpa da semente de algodão"36. A descrição minuciosa do trabalho das máquinas aparece num tom de envolvimento e sedução diante dos movimentos ritmados:

As caldeiras, segundo nos informaram, têm força de sessenta cavallos, e dão energia a um poderoso motor, que, com o auxilio de um forte e largo relho, imprime movimento a um grosso e alto eixo central, de ferro. Passa esse eixo pela parte superior do segundo pavimento do edificio, atravessando-o em quase todo a sua extensão; e por sua vez, por meio de outros relhos, que se adaptam ás diversas machinas, em numero de oito ou dez, pode-se por todas em simultaneo movimento, fazendo-as executar, com absoluta regularidade e perfeição, as diferentes operações a que são destinadas. ${ }^{37}$

Fortes imagens estão impressas nesses fragmentos retirados das "impressões de viagem" de Antonio Neves. O vapor no interior da fábrica, a alta temperatura, os corpos hercúleos e suados, os mecanismos e automatismos, o barulho das máquinas, tudo isso alterando a percepção, interferindo nos sentidos do observador, não somente na visão e na audição, mas também no olfato: o cheiro que exalava não era outro senão o "cheirozinho de progresso". E o observador não permanecia inerte, ele participava ativamente daquela orquestra de máquinas que incitava a imaginação sobre um futuro possível para o alto sertão. Um vislumbre de progresso e modernização em meio às constantes sensações de estagnação e abandono.

Constituía aquilo tudo um sinal revigorante de esperança numa época de incertezas, pois era preocupante a acentuada mobilidade populacional, com levas de migrantes para o sudeste do país. Para aquecer ainda mais os ânimos, vislumbrava-se a construção de uma via férrea que passasse por Caetité e Bella Flor, indo rumo ao rio São Francisco. Ali, naquele rincão do país, uma fábrica promissora e uma ferrovia seriam determinantes para o progresso tão desejado. Basta lembrar que o Boletim Comemorativo da Exposição de 1908 indicava os telégrafos, as vias férreas, as cidades e os correios como fatores decisivos no desenvolvimento nacional. ${ }^{38}$

\footnotetext{
${ }^{36}$ NEVES, “Impressões de viagem", p. 2.

${ }^{37}$ NEVES, “Impressões de viagem”, p. 2.

${ }^{38}$ BOLETIM Commemorativo da Exposição Nacional de 1908. Rio de Janeiro: Typografia da Estatística, 1908.
} 
Aqueles que se deixavam seduzir pelas promessas dos lugares distantes, ou que não viam mais alternativas para a melhoria de suas condições de vida no alto sertão, embrenhavam-se pelos caminhos que levavam a São Paulo, para ficar no exemplo mais citado. Quanto aos menos aventureiros ou com melhores condições, desejosos por outras possibilidades de experiência, saudavam iniciativas auspiciosas, como a do "benemérito moço" Mario Teixeira. Iniciativa prometedora "das maiores vantagens, e que certamente assignalará o advento de uma acentuada phase do progresso d'esta esquecida e atrazada zona; - affagada agora pela grata esperança da vinda da via ferrea, para complemento da nossa definitiva era de prosperidade". ${ }^{39}$

\section{O trem que não chegou}

Projetadas para os mais distantes rincões do Brasil, percorrendo o "interior, galgando as serras, transpondo os rios, conquistando para a civilisação os sertões bravios, desertos e demandando as fronteiras", ${ }^{40}$ as vias férreas assumiam um papel muito além de sua dimensão técnico-industrial. Evidenciavam-se como um esforço político de conquista de território e projeto civilizacional, como meio de articulação e desenvolvimento econômico e como a metonímia do progresso que perdurou até meados do século XX. Instilaram especialmente a alteração da percepção espaço-temporal com os efeitos da velocidade. ${ }^{41}$ Entretanto, a rapidez do trem de ferro sumindo no horizonte ou chegando na estação contrastava com a espera e a demora na construção das ferrovias. Em outras palavras, tratava-se de um "contraste entre a noção da inevitabilidade do progresso [...] e a percepção das limitadas realizações de empreendimentos ferroviários". ${ }^{42}$ A ausência de tais empreendimentos em muitos lugares do interior fortalecia ainda mais a imagem de sertão como lugar do atraso e do abandono. ${ }^{43}$ Permanecia a sensação de quase isolamento, sem a possibilidade de interligação e desenvolvimento dos municípios, tampouco de fazer das pequenas cidades interioranas um centro irradiador da energia moderna.

\footnotetext{
${ }^{39}$ NEVES, “Impressões de viagem", p. 2.

${ }^{40}$ BOLETIM Commemorativo da Exposição Nacional de 1908, p. V.

${ }^{41}$ Cf. HARDMAN, Trem-fantasma, p. 33-61.

${ }^{42}$ LIMA, Pablo Luiz de Oliveira. A máquina, tração do progresso: memórias da ferrovia no Oeste de Minas entre o sertão e civilização, 1880-1930. Dissertação (Mestrado em História), Universidade Federal de Minas Gerais, Belo Horizonte, 2003, p. 20.

${ }^{43}$ Cf. NAXARA, Márcia Regina Capelari. Fragmentos de "Histórias e Paisagens do Brasil" (percurso de pesquisa). In: Anais do primeiro e do segundo encontros de pós-doutores do PPGH/UFF. Niteroi-RJ: PPGH/UFF, 2009.
} 
Nos lugares em que a ferrovia estava presente, o ritmo de vida das pessoas parecia alterado de tal modo que a relação com as grandes cidades tornara-se mais constante e dinâmica não somente do ponto de vista econômico, mas também cultural. Nesse sentido, vale citar um pequeno conto reproduzido no jornal A Penna em 1927, que ilustra a dimensão das ferrovias no imaginário dos habitantes interioranos. 0 autor, que assina como José Casusa, narra as desventuras de dois personagens, moradores de um povoado nos arredores do município de Alagoinhas, em uma viagem que fizeram à capital baiana. Um deles, o Apolônio, ia com frequência à capital para vender "feijão, milho, farinha, abanos, gallinhas, toucinho, o diabo [...] na feira de Agua de Meninos", por isso já conhecia bastante o modo de vida urbano, o que o livrava de situações vexaminosas entre as gentes citadinas. O seu amigo Domingos alimentava o desejo de conhecer a Bahia [Salvador], pois, "de cidade só conhecia Alagoinhas e Inhambupe." Com o intuito de finalmente realizar a visita desejada, Domingos tratou com Apolônio para que pudesse acompanhá-lo na próxima viagem. No dia marcado,

[Domingos] Arrumou o bahú de "folha" e esperou. Não comeu naquelle dia, nem dormiu naquella noite, o coração pulando de alegria.

Pela madrugada despediu-se dos paes e da noiva - a Jula; montou e foi bater á porta do Appolonio.

Chegaram em Alagoinhas e tomaram o trem de 4 e 30, em segunda classe. Quando já iam alli pelo Catú, amanhecia.

Domingos, debruçado á janella do carro, sorria, maravilhado do espetaculo! E' verdade! Que coisa bonita era um trem de ferro correndo!

[...] A ânsia em que estava de conhecer a capital, e as bellezas que ia surpreendendo, no correr da viagem, não lhe dava vontade de mais nada.

Quando o Mingo viu o mar, voltou-se para dentro do carro, com uma grande admiração estampada na face, e exclamou:

- Polonho, meu veio! ô açudão macho!

Appolonio ficou morto de vergonha, vendo que os passageiros sorriam, compassivos, e explicou ao pobre estúpido:

- Aquillo não é açude: é o má.

Domingos, sem soffrer decepção, voltou-se para o mar e prorrompeu num enthusiasmo:

- Ô marzão veio besta! ${ }^{44}$

Mantendo o mesmo tom cômico, o autor continua a narrar os vários vexames de Domingos acompanhados dos constrangimentos de Apolônio nas

${ }^{44}$ CASUSA, José. “Casos: Quem viu o Appollonio?”. A Penna, Caetité-BA, 29 de set. 1927. 
ruas de Salvador, no bonde, diante dos automóveis, na pensão onde repousaram e quando usaram o elevador Lacerda. Guardados outros alcances desse conto, ele sinaliza o significado de uma rede ferroviária para os municípios por ela servidos. ${ }^{45}$

No início da década de 1910 havia uma impressão geral de que finalmente chegaria a Caetité, e sem mais demora, uma linha da Estrada de Ferro Central da Bahia, dali seguindo até o rio São Francisco, em Malhada. Se assim fosse, a Empreza Industrial Sertaneja estaria duplamente contemplada: por um lado, os produtos poderiam ser escoados através da linha em direção ao Recôncavo e a Salvador; por outro, pela linha rumo ao São Francisco, conquistando mercados em Minas ou ainda mais longe.

O projeto da Estrada de Ferro Central da Bahia remontava a meados do século XIX, quando o trem de ferro transformou-se na imagem mais duradoura que mensurava a difusão do maquinismo pelo mundo. A Central da Bahia constituía o segundo empreendimento ferroviário no território baiano e o "seu traçado obedeceu à lógica locacional de conectar o interior da província da Bahia, através dos portos fluviais do Recôncavo, com a capital, Salvador. A estrada de ferro deveria se apoiar na rede das estradas gerais e caminhos de tropa do sertão". ${ }^{46}$

Inicialmente ao encargo da iniciativa privada, a construção da via férrea começou em 1867 com um trecho ligando Cachoeira, nas bordas do Recôncavo, a Feira de Santana, sendo o tráfego aberto definitivamente nove anos mais tarde. A linha principal, no entanto, seria em direção à Chapada Diamantina, mas seguiu de São Félix - cidade ao lado de Cachoeira - na direção leste-oeste e, anos depois, rumou no sentido sudoeste em direção a Minas Gerais. De acordo com Francisco Zorzo, "o segmento até Bandeira de Melo foi aberto ao tráfego em 1887 e o segmento até Machado Portela, em 1888, ponto onde a estrada estacionou por trinta anos, com cerca de 320 quilômetros de extensão". ${ }^{47}$

Em 1902, por razões estratégicas e devido à necessidade de consolidar uma efetiva rede ferroviária, o governo federal resgatou a estrada e arrendou-a a particulares. Somente em 1928 a ferrovia chegou ao povoado

\footnotetext{
${ }_{45}$ Neste conto de José Casusa, trata-se da Estrada de Ferro da Bahia ao São Francisco, a primeira via férrea do estado, iniciada em 1856.

${ }^{46}$ ZORZO, Francisco Antônio. O movimento de tráfego da empresa da Estrada de Ferro Central da Bahia e seu impacto comercial: das iniciativas privadas inaugurais à encampação estatal (1865-1902). Sitientibus, Feira de Santana, n. 26, jan./jun., 2002, p. 64.
}

${ }^{47}$ ZORZO, "O movimento de tráfego...", p. 64. 
de Contendas. Ainda no século XIX, o plano geral da ferrovia tinha sofrido uma alteração significativa:

O traçado original dirigia-se para o interior da província acompanhando o vale do rio Paraguaçu até cruzar a Chapada Diamantina e dali se encaminharia, a Oeste, para o Rio São Francisco. Porém, a partir do final dos anos 1880, surgiu uma proposta, que foi se tornando cada vez mais preponderante, contrária ao encaminhamento na direção Oeste e, em vez disso, dirigir-se ao Sul pela zona de Brejo Grande, Rio de Contas e Caetité e terminar encaminhando-se para o Norte de Minas Gerais. O comércio dessa zona era tradicionalmente conectado a Cachoeira por meio das tropas que passavam por Maracás. ${ }^{48}$

Isso gerou uma espera de anos a fio por parte dos moradores do alto sertão estimulados pela expectativa de poder finalmente contar com uma linha férrea. Por outro lado, colocou em evidência todas as fragilidades da empreitada. Nas duas primeiras décadas do século XX não houve nenhum avanço significativo na construção da obra, demonstrando claramente os embaraços de levar a cabo o projeto de extensão da ferrovia até o norte de Minas Gerais, para ali, na cidade de Monte Azul, entroncar-se com a Linha do Centro da Estrada de Ferro Central do Brasil. Muito mais do que fatores físicos, essa demora pode ser explicada pela falta de investimentos e de interesse especialmente por parte do governo federal que havia encampado a empresa a partir de 1902.

O projeto, todavia, foi marcado por desentendimentos nas duas primeiras décadas do século XX. Inicialmente, a ferrovia deveria alcançar o vale do rio Paraguaçu, chegando até o São Francisco. Na segunda proposta que ganhou força desde o final do século XIX, ela se encontraria com a Linha do Centro, em Minas Gerais. No entanto, durante a década de 1910, documentos sinalizam que o traçado ainda obedecia ao projeto original, ou seja, ao invés de dirigir-se à cidade mineira de Monte Azul, a linha férrea terminaria em Malhada, no município baiano de Carinhanha, às margens do rio São Francisco.

Os estudos da viabilidade da linha de Machado Portela até Caetité foi chefiado pelo engenheiro caetiteense Antonio Rodrigues Gomes Ladeia. Em 1912, as notícias eram animadoras: "a companhia tem os capitaes levantados, acha-se com muito material adquirido e apenas aguarda a entrega dos estudos para metter mãos á obra". ${ }^{49} \mathrm{Um}$ ano mais tarde já tinham sido enviados ao Ministério da Viação os estudos de 600 quilômetros para a construção da

\footnotetext{
${ }^{48}$ ZORZO, "O movimento de tráfego...", p. 64-65.

49 “Viação férrea”. A Penna, Caetité-BA, 10 de mai. 1912, p. 2.
} 
linha, mas somente 90 quilômetros foram aprovados. Mesmo assim, a obra não avançou, deixando em alerta as autoridades locais:

Sendo de urgentissima necessidade a prompta penetração dessa via-férrea, único salvateiro de nossa zona, que acha-se ameaçada de despovoamento á falta de trabalho: telegrapharam as Intendencias de Monte-Alto, Carinhanha, Caetité e Umburanas pedindo que, ao mesmo tempo que se trabalha na construcção a partir de Machado Portella, sejam encetados os trabalhos de Malhada, á margem do S. Francisco a encontrarem com os outros encetados. [...].

Lemos n'A Tarde que em vista dos telegrammas dos Intendentes acima, o Dr. Seabra dirigiu-se ao Ministro da Viação, que promptamente mandou atacar o serviço nos dous sentidos. Fala-se alli em Barra, mas suppomos ser troca de nome de lugar. ${ }^{50}$

Como já foi assinalado, o trem de ferro, metonímia do progresso, era o grande desejo alimentado por muitos moradores do alto sertão. Com ele, vislumbrava-se uma guinada efetiva por onde quer que passasse. A sua construção beneficiaria especialmente os empreendimentos fabris, grandes ou pequenos, que poderiam escoar sua produção e elevar os lucros, como ambicionavam os acionistas da Empreza Industrial Sertaneja. Galgando a serras de Rio de Contas, passando por Caetité até chegar em Malhada, toda a "riqueza adormecida" poderia ser explorada, trabalhada e exportada. Contudo, não era clara a fronteira entre desejo realizável e quimera. A ferrovia revelava-se como o remédio de todos os problemas econômicos enfrentados, a possibilidade fantástica de uma mudança radical na vida social do alto sertão.

No entanto, os trabalhos tardavam muito, embora a companhia responsável dissesse o contrário. Passados três anos desde a terraplanagem dos noventa quilômetros aprovados para o avanço dos trilhos, e mais de um ano de espera pela inauguração do trecho, a situação gerava indignação e pessimismo:

N’A Tarde de 22 do passado [no] local 'A rede da viação bahiana' lemos o trecho seguinte: 'Linha de Machado Portella e Carinhanha. Os trabalhos foram atacados em 90 kilometros, estando muito adeantados o movimento de terras e as obras d'arte. A collocação de trilhos já começou e está feita em 6 kilometros e continua muito activamente, de forma que a inauguração de 90 kilometros seja tão rápida quanto possivel'. [...]

Cremos com muito bons fundadamentos que 'a rapidez quanto possivel' de que trata a direcção será, pelo menos de uns dez annos. N’esse andar, quando nos chegará a carangueijola? Há tanta esperança de realisação desse melhoramento, que está o governo cogitando uma estrada de rodagem d'esta Cidade ao rio

50 "Central-Bahia". A Penna, Caetité-BA, 11 de abr. 1913, p. 3. O jornal A Tarde, a que o texto faz referência, era (e ainda é) um dos principais jornais baianos publicado em Salvador. 
de S. Francisco no mesmo traçado da ronceira via ferrea. Somente cegos ou [desavisados] podem crer n'essas reiteradas promessas de estrada de ferro..$^{51}$

Em 1923, a mudança no traçado da ferrovia, que entroncaria com a Central do Brasil, apareceu definitivamente confirmada. Entretanto, no novo plano, a linha distanciaria bastante de Caetité, dobrando-se para o sul depois de passar por Bom Jesus dos Meiras (atual Brumado). A justificativa para tal mudança baseou-se no encurtamento do trecho e dos dispêndios até chegar a Monte Azul. A principio, a imprensa de Caetité pareceu receber a ideia sem maiores problemas, uma vez que "a estrada que se vae construir, entroncando-se na principal artéria ferroviária do Brasil, será de tal importância que o seu raio de acção se estenderá por extensa faixa da nossa região". ${ }^{52} \mathrm{O}$ autor da matéria relembra os avanços da relação com a capital federal graças à estação na cidade de Pirapora, nas margens mineiras do São Francisco, e as embarcações a vapor nesse rio, responsáveis pela redução do tempo de viagem de dois ou três meses para cerca de seis dias. A nova linha facilitaria ainda mais as condições de transporte:

Se tantos proveitos já colhemos até aqui, maiores ainda colheremos em toda a região quando tivermos mais proxima de nós uma estação de estrada de ferro á qual chegaremos em menos de dous dias quer queiramos ir á Bahia, quer ao Rio. A nossa estrada desta Cidade até alem do Caculé é naturalmente de rodagem como se sabe, pois por ella transitam facilmente pesados carros tirados por juntas de bois. Sendo ella em toda á sua extensão de solo firme e massiço, na maior parte da terra argiloferruginosa, poderá, com pequeno despendio, ser apparelhada para a vehiculaçao de auto-caminhões e outros vehiculos modernos de modo a alcançarmos em um dia a estação mais proxima pelo lado oriental da serra". ${ }^{53}$

Um ano foi o tempo necessário para o autor prognosticar as perdas que daí adviriam para o município, que ficaria à mercê de muares e carros de bois, continuando inaproveitada as riquezas da terra devido à ausência de transportes modernos:

O antigo traçado da nossa via ferrea de penetração satisfazia a todas essas exigências, d'ella auferindo grandes vantagens todos os municipios do alto sertão. $O$ novo traçado, porem, não satisfaz essas instantes exigencias porque a linha, tendo por fim primordial, senão exclusivo, ligar a nossa rede ferroviaria

\footnotetext{
51 “Nossa via-ferrea”. A Penna, Caetité-BA, 18 de jan. 1917, p. 4.

${ }^{52}$ GUMES, João. “Vias-ferreas”. A Penna, Caetité-BA, 11 de out. 1923, p.1.

${ }^{53}$ GUMES, "Vias-ferreas", p.1.
} 
á do Estado de Minas, procurou um trajeto pouco mais curto que, entanto, offerece á construcção inumeros embaraços que orçam por obstáculos. ${ }^{54}$

Inúmeras vezes citada como a "única salvação para o nosso progresso", podemos imaginar o alcance dessa frustração para os entusiastas da ferrovia em Caetité e em outros municípios. Contudo, os anos de espera, a descrença e o pessimismo diante do empacamento das obras, além dos desentendimentos quanto ao traçado que deveria ser levado a cabo, fizeram com que alternativas de transporte fossem pensadas. Estradas de rodagem mais amplas que favorecessem o trânsito de automóveis foram insinuadas no final da década de 1910, mas só vieram a ser pensadas com maior afinco nos anos 1920, e mais efetivamente em fins dessa década com a chegada de agentes da Ford, em Riacho de Santana, e da Chevrolet, em Caetité.

A linha do sul, em direção a Minas Gerais, seria concluída somente entre as décadas de 1940 e 1960. Quanto ao trecho rumo ao oeste ficou empacado num projeto distante no tempo. Absolutamente descrente, João Gumes sintetizou o quadro da empreitada em 1914: "A Central Bahia acha-se escangalhada, com o leito esborrodando, os dormentes apodrecidos, os trilhos carcomidos e o material rodante, que serve há cerca de trinta annos, já imprestavel". E concluiu lamentando: "talvez riam-se de nós aquelles que acham-se cercados de todo o conforto; de nós, pobres tabaréos que temos a velleidade de desejar o luxo de uma estrada de ferro". ${ }^{5}$

\section{Considerações finais}

O empreendimento de Mario Teixeira com a Empreza Industrial Sertaneja foi decerto bastante arrojado, mas teve lugar numa época de grandes expectativas. Talvez pela região em que a ideia nasceu e onde foi efetivada, o alto sertão baiano, pode-se notar alguma surpresa. Mas não de todo surpreendente, uma vez que a ampliação dos escopos econômico e civilizacional colocou o sertão na agenda da República. Foi então que a tecnocracia ganhou ares promissores. Nas plagas interioranas, alguns coronéis não perdiam de vista esse aspecto. Se insistiam, por um lado, nos velhos laços afetivos e na observância das relações pessoais como forma de manter o poder local, por outro, estavam atentos à onda auspiciosa dos conhecimentos técnicos e científicos. Investir na educação dos descendentes era, evidentemente, uma forma de assegurar o poder em uma de suas variadas dimensões. No caso de Mario, sua

\footnotetext{
${ }^{54}$ GUMES, João. "Estrada de ferro”. A Penna, Caetité-BA, 10 de jul. 1924, p.1

${ }^{55}$ GUMES, João. “Situação angustiosa”. A Penna, Caetité-BA, 25 de jun. 1914, p.1.
} 
formação em engenharia não foi por escolha às escuras nesse amplo contexto de modernização técnica. Como ele, outros filhos do coronel Deocleciano Pires Teixeira, seus irmãos, seguiram os caminhos do engenheiro.

Mais uma vez citando Faoro, era a modernização que se tinha em vista e não a modernidade, pois havia uma clara manifestação do desejo de conduzi-la, sem lugar para as vozes de outras camadas sociais que não fossem a dirigente. Mas isso não significa supor, de modo redutivo, apenas um quadro de conflito de forças opostas, tampouco supor que essas forças eram claramente distinguíveis. Na construção de um imaginário moderno havia o compartilhamento de inúmeros desejos, cujo mais ressoante era o desejo por uma vida melhor. No entanto, como sublinhou Willi Bolle a propósito do pensamento de Walter Benjamin, "o século XX, tampouco como o anterior, não soube corrigir as discrepâncias entre as enormes possibilidades abertas pelo progresso da técnica - as aspirações da modernização - e a falta efetiva de criação de um mundo melhor". ${ }^{56}$ Homens como Mario Teixeira e João Gumes, cada um à sua maneira, acreditaram e amarguraram as promessas de um mundo melhor com o progresso técnico. Como que acometidos por uma espécie de vislumbre de futuro, imaginaram o trem cortando as serras de Caetité e o baixio de Bella Flor, misturando sua fumaça com a fumaça das chaminés da fábrica, rasgando as entranhas e seguindo por entre a selva catingueira até desembocar no rio São Francisco.

Artigo recebido para publicação em 10/02/2017

Artigo aprovado para publicação em 07/08/2017

${ }^{56}$ BOLLE, Willi. Fisiognomia da metrópole moderna: representação da história em Walter Benjamin. São Paulo: Edusp, 1994, p. 24. 